be done is to get into the young mind some notion of what animal and vegetable life is. You have to consider in this matter practical convenience as well as other things. There are difficulties in the way of a lot of boys making messes with slugs and snails; it might not work in practice. But there is a very convenient and handy animal which everybody has at hand, and that is himself; and it is a very easy and simple matter to obtain common plants. Hence the broader facts of anatomy and physiology can be taught to young people in a very real fashion by dealing with the broad facts of human structure. Such viscera as they cannot very well examine in themselves, such as hearts, lungs, and livers, may be obtained from the nearest butcher's shop. In respect to teaching something about the biology of plants, there is no practical difficulty, because almost any of the common plants will do, and plants do not make a mess-at least they do not make an unpleasant mess; so that, in my judgment, the best form of Biology for teaching to very young people is elementary human physiology on the one hand, and the elements of botany on the other; beyond that $\mathrm{I}$ do not think it will be feasible to advance for some time to come. But then I see no reason why in secondary schools, and in the Science Classes which are under the control of the Science and Art Department-and which I may say, in passing, have, in my judgment, done so very much for the diffusion of a knowledge over the country-I think that in those cases we may go further, and we may hope to see instruction in the elements of Biology carried out, not perhaps to the same extent, but still upon somewhat the same principle as wc do here. There is no difficulty, when you have to deal with students of the ages of 15 or 16 , in practising a little dissection and getting a notion, at any rate, of the four or five great modifications of the animal form, and the like is true in regard to plants.

While, lastly, to all those who are studying biological science with a view to their own edification merely, or with the intention of becoming zoologists or botanists; to all those who intend to pursue physiology-and especially to those who propose to employ the working years of their lives in the practice of medicine-I say that there is no training so fitted, or which may be of such important service to thcm, as the thorough discipline in practical biological work which I have sketched out as being pursued in the laboratory hard by.

I may add that, beyond all these different classes of persons who may profit by the study of Biology, there is yet one other. I remember, a number of years ago, that a gentleman who was a vehement opponent of Mr. Darwin's views and had written some terrible articles against them, applied to me to know what was the best way in which he could acquaint himself with the strongest arguments in favour of evolution. I wrote back, in all good faith and simplicity, recommending him to go through a course of comparative anatomy and physiology, and then to study development. I am sorry to say he was very much displeased, as people often are with good advice. Notwithstanding this discouraging result, I venture, as a parting word, to repeat the suggestion, and to say to all the more or less acute lay and clerical "paper-philosophers" " who venture into the regions of biological controversy-Get a little sound, thorough, practical, elementary instruction in biology.

\section{T. H. HuXLEY}

Writers of this stamp are fond of talking about the Baconian method. I beg them therefore to lay to heart these two weighty sayings of the herald of Modern Science :-

Syllegisuus ex propositionibus constat, propositiones ex verbis, verba notionum tesseræ sunt. Itaque si notiones ipsa (id quod basis rei est) confusa sint et temere a rebus abstracta, nihil in is quæ superstruuntur es firmitudinis."-" Novum Organon," ii. I4.

"Huic autem vanitati nonnulli ex modernis summa levitate ita indulserunt, ut in primo capitulo Geneseos et in libro Job et aliis scripturis sacris, philo sophiam naturalem fundare conati sint; inter vivos querentes mortuc.". Ibid., 65.

\section{EXPERIMENTS WITH THE RADIOMETER}

\author{
I.
}

A BSTRACTS of my earlier papers on "Repulsion A Resulting from Radiation" having appeared in NATURE, it has been suggested that an account of my later researches, which place the subject in such a different light, may also prove of interest.

It has already been shown that if the air is expelled from a large bulb containing a suspended bar of pith, and a lighted candle is placed about 2 inches from the globe, the pith bar commences to oscillate to and fro, the swing gradually increasing in amplitude until the dead centre is passed over, when several complete revolutions are made. The torsion of the suspended fibre now offers resistance to the revolutions, and the bar commences to turn in the opposite direction. It has been found, however, that very little movement takes place until the vacuum is so good as to be almost beyond the powers of an ordinary air-pump to produce, and that, as the vacuum gets more nearly absolute, so the force increases in power. The most obvious explanation therefore is, that the repulsive action is due to radiation; but at a very early stage of my investigation I found that the best vacuum I had succeeded in producing might contain enough matter to offer resistance to motion, and in describing an experiment in a paper sent to the Royal Society on February 5, 1876, I said that the impression conveyed to my mind was that the torsion beam was swinging in a viscous fluid, and the repulsion caused by radiation was indirectly due to a difference of thermometric heat between the black and white surfaces of the moving body, and that it might be due to a secondary action on the residual gas.

I have recently succeeded in producing such a complete exhaustion that I have not only reached the point of maximum effect, but gone so far beyond it that repulsion nearly ceases, and the results I have thus obtained seem to show conclusively that the true explanation of the action of the radiometer is that given by Mr. Johnstone Stoney, according to which the repulsion is due to the internal movements of the molecules of the residual gas. When the mean length of path between successive collisions of the molecules is small compared with the dimensions of the vessel, the molecules, rebounding from the heated surface, and therefore moving with an extra velocity, help to keep back the more slowly moving molecules which are advancing towards the heated surface; it thus happens that though the individual kicks against the heated surface are increased in strength in consequence of the heating, yet the number of molecules struck is diminished in the same proportion, so that there is equilibrium on the two sides of the discs, even though the temperature of the faces are unequal. But when the exhaustion is carried to so high a point that the molecules are sufficiently few, and the mean length of path between their successive collisions is comparable with the dimensions of the vessel, the swiftly-moving, rebounding molecules spend their forces in part or in whole on the sides of the vessel; and the onward crowding, more slowly-moving molecules are not kept back as before, so that the number which strike the warmer face approaches to, and in the limit equals, the number which strike the back cooler face; and as the individual impacts are stronger on the warmer than on the cooler face, pressure is produced, causing the warmer face to retreat.

Before referring at length to the experiments which led to my adopting the above theory, I will describe some effects of dark heat, \&c., on the radiometer. In a paper I sent to the Royal Society on January 5, I876, and which is now being published in the Philosophical Transactions of the Royal Society, about seventeen pages are occupied with the description of my experiments with various forms of this instrument. In the present paper I propose only to refer to a few typical experiments made during the year 1875 . 
To show the action of dark heat on the radiometer, a candle was placed at such a distance from the instrument that the arms would make one revolution a minute. A small glass flask of boiling water was then placed halfan-inch from the bulb. The revolutions instantly stopped, two of the arms setting equidistant from the hot-water flask. The flask of water was removed. As the portion of the bulb which had been heated by the hot water cooled, the white surface gradually crept nearer and nearer to it, the superior repulsion of the candle on the black discs urging the arms round, and acting in opposition to the repulsion of the hot glass to the white disc. At last the force of the light drove the white disc with difficulty past the hot spot of glass. Rotation then commenced, but for some revolutions there appeared to be a difficulty in the white discs passing the spot of glass which had been warmed by the hot water; and the flask of boiling water being replaced in its position half-an-inch from the bulb of the radiometer, the rotation immediately stopped.

The instrument having become cool, the candle was again placed in position, so that it produced one revolution in a minute. The finger was then pressed against the side of the bulb, and as the spot of glass got warm, the white surface experienced more and more difficulty in getting past it, until at last one refused to pass, and the arms came to rest.

The instrument was again allowed to cool, and the revolutions recommenced at the usual speed (the laboratory in which this was tried was somewhat cold). I then came from a warm room, and stood a foot from the radiometer, watching it. In about a minute the radiant heat from my body had warmed the side of the bulb nearest to me sufficiently to cause an appreciable difficulty in the movement, and soon the revolutions stopped. The same effect has been observed if the radiometer is brought into a very warm room and placed near a cold window. If the daylight is feeble, the instrument not very sensitive, or an observer stands near the instrument, an appreciable sticking is observed as the white discs come near that part of the bulb which is the warmest.

These experiments show that many precautions are necessary to guard against the interfering action of uncqual heating of the radiometer when it is being used for accurate measurements.

Having found such an antagonistic action of dark heat, I tried the action of ice. This is equivalent to warming the opposite side of the instrument. A lump of ice was brought within half an inch of the bulb on the opposite side to the candle. The revolutions got slower, until at last the movement stopped altogether, one arm pointing direct to the ice, and being apparently held there by a powerful attractive force. Bringing the candle nearer caused the arms to oscillate a little, and when it was almost close to the bulb the force of the light overcame the action of the ice, and the arms revolved again, but irregularly, and with jerks, the discs moving quickly to the ice and leaving it with difficulty. In this action of ice no preference was noticed for either the black or white suiface.

A very delicate radiometer, in 2-inch bulb, was placed in a sufficient light to allow it to be seen distinctly, but not cnough to cause it to move. I then came out of a warm room and stood near it. In a few seconds it began to move slowly round in the negative direction, i.e. the black discs advanced instead of retreated. On moving away from the instrument the rotation gradually stopped. $I$ again approached it, and held one hand an inch from the bulb. Rotation soon commenced, but still in the reverse way. These experiments were frequently repeated and always with the same results.

When the instrument was at rest I came quickly to it, and gently breathed on the bulb. There was a slight movement in the normal direction, but this stopped directly, and the arms then revolved the reverse way for more than a minute, performing three or four complete revolutions.

A glass shade four inches in diameter was held over a gas-flame till the air inside was warm, and the inner surface dim with steam. It was then inverted over the radiometer. Rotation commenced the reverse way, and kept up for several minutes. The glass shade was then dried inside, and heated uniformly before a fire until it had a temperature of about $50^{\circ} \mathrm{C}$. It was then inverted over the radiometer, Reverse rotation instantly commenced, and kept up with some vigour for more than five minutes, diminishing in speed until the shade had cooled down to the temperature of the surrounding air.

The same experiment was repeated, and whilst the arms were in full negative rotation, a lighted candle was slowly brought near it. When three feet off the negative rotation slackened. When the candle was about two feet off the arms became still, and when nearer than two feet the instrument rotated normally, the antagonism between the action of the hot shade and the lighted candle was perfect ; by moving the candle to and fro it was easy to cause the radiometer to move in one direction or the other, or to become still.

I now tried the action of a radiometer the moving parts of which were made of a good conductor of heat, such as a metal, instead of pith, which is a bad conductor of heat. I selected thin rolled brass as the material wherewith to make the arms and discs of a radiometer. The parts were all fastened together with hard solder, and no cement or organic matter was used, so that if necessary the instrument could be submitted to a high temperature without injury. The moving portion weighed $13^{\circ} \mathrm{I}$ grains. One side of the discs was silvered and polished, the other side being coated with lampblack. The apparatus was exhausted with a charcoal reservoir attached. A candie $\mathrm{I} \frac{1}{2}$ inch from the bulb caused it to revolve about once a second, the black surface being repelled in the normal manner.

Standing in a rather dark cold room, it was covered with a warm glass shade, and it immediately began to revolve the negative way, but very slowly. A few drops of ether poured on the bulb caused the arms to move rather rapidly the normal way. A hot shade put over whilst it was thus moving caused it to stop: and then begin moving the reverse way. A small non-luminous gas flame was held vertically beneath the apparatus, so that hot air should ascend and wrap round the bulb on all sides. The arms now revolved the reverse way.

The brass radiometer being somewhat heavy, one was made of aluminium, the moving parts being hard soldered as before. A siphon-gauge was attached, and the apparatus connected direct on to the pump by a spiral, no charcoal tube being used. One side of the wings was bright aluminium, and the other was lampblacked. When exhausted the arms revolved very quickly to a candle a few inches off, the black being repelled. On removing the candle the arms stopped and immediately commenced revolving the reverse way, keeping up rotation for more than ten minutes, and being little inferior in speed to what it was when the candle shone on it. The whole of the bulb was heated with a Bunsen burner; whilst it was getting hot the aluminium arms revolved rapidly in the normal direction, but as soon as the source of heat was removed and cooling commenced, rotation set up in the reverse way, and continued with great energy till the whole thing was cold. It appeared as if the reverse movement during the cooling was equal in energy to the normal movement as it was being heated.

A little ether was poured on the bulb of a very sensitive pith radiometer as it was standing still in a faint light. The evaporation of the ether caused a chilling of the in strument and a rapid abstraction of heat from the arms. They commenced to move in the normal direction and 
increased quickly in speed until they revolved at a rate of one in four seconds. This movement kept up for several minutes, and as it slackened it could at any time be revived by a few drops of ether on the bulb. When in rapid movement a hot glass shade was placed over the radiometer the movement slackened, the arms quickly came to rest and immediately revolved in the reverse direction, acquiring a speed of about two revolutions a minute, and keeping up this reverse movement for more than ten minutes.

I again set the instrument in rapid rotation by dropping ether on the top of the bulb and applied the tip of one finger to the side of the bulb for ten seconds. The rotation stopped, and I could not start it again for some minutes, although I dropped ether on the bulb, several times in the interval. When the radiometer had once more acquired the temperature of the air I dropped ether on the bulb, not in the centre, but so that the ether wetted only half of the bulb. The arm which was nearest to the part most chilled by the ether rushed towards that part ind remained, as it were, fixed opposite to it, refusing to move away, although I tried to equalise the temperature by dropping ether on the other parts of the bulb, and to drive it round by bringing a candle near. Not until the candle came within six inches of the bulb did the arms begin to rotate, which they then did with a rush, as if suddenly relieved from a state of tension.

I have referred to a sufficient number of experiments to show that a metal radiometer rotates in a negative direction on being exposed to the action of dark heat, the black advancing and continuing to do so until the temperature has become uniform throughout. On removing the solirce of heat, the fly commences to revolve with rapidity the positive way, the black this time retreating as it would if light shone on it.

To determine whether at temperatures beíween $250^{\circ}$ and $100^{\circ}$ the repellant action of radiant heat was about cqual on black and on white surfaces, I used a radiometer having pith discs blackened on one side. A tube was sealed into one side of the bulb, and having two stout platinum wires passing along it, sealed their whole length in glass to prevent leakage of air into the interior of the apparatus. At the ends of the wires a spiral of fine platinum wire was fastened, and the other ends terminated in loops outside. The bulb was perfectly exhausted, and the following experiments were tried :-

A resistance-coil was so adjusted that a battery would keep the platinum spiral at a bright red heat. The arnas of the radiometer, which were before quite still, moved rapidly until two of the discs were one on each side of the hot spiral, the black disc being further off than the white disc. The resistance was then gradually increased, and as the temperature of the spiral diminished, the black disc gradually approached the spiral, until, when the temperature was just at the point of visible redness in a dark room, the black and white discs were practically equidistant from the spiral. On diminishing the resistance, the same phenomena took place in inverse order.

The resistance was again adjusted to give a bright red spiral, and the contact key kept pressed down. A lighted match was momentarily brought near the bulb, so as to start a movement. Rotation of the arms commenced, and kept up, with some energy, at the rate of about one revolution in five seconds, equal to that given by a candle eight inches off. There was some little hesitation, as the white side came up to the spiral, but this was scarcely noticed when the speed had become steady. The resistance was now slightly increased. The speed became slower as the temperature of the spiral diminished, and the hesitation, as the white approached the spiral, became more apparent. The resistance was further increased, with the effect of making rotation still slower, bringing the temperature of the spiral down to just visible redness in the dark. The speed of rotation again slackened; at each approach of the white surface to the spiral it appeared to stop, hesitate, and then get past with a rush. Thus it went on for a few revolutions, until one white disc, a little nearer, prhaps, than the others, was not able to pass, and the arms, after a few oscillations, came to rest, the black and the white suriaces being, as near as I could judge, equidistant from the hot spiral.

I now tried to ascertain whether, at temperatures lower than $100^{\circ} \mathrm{C}$., the white would be repelled most.

The resistance of the coil was increased again, and the position of the arms in respect to the spiral noticed. When so much resistance was offered to the passage of the current that the spiral. would only be just warm, I fancied the white was further from it than the black, but the observation was not satisfactory at higher temperatures; up to visible redness the repulsion was equal for each. Breathing on the bulb sent the arms rapidly round the reverse way.

The battery was disconnected from the instrument, and one end of a wire was atiached to one of the platinum. loops, the other end of the wire being connected to the prime condluctor of a frictional electrical machine. A few turns of the handle sent the arms flying about wildly, first in the positive and then in the negative direction, till finally one pointed steadily to the platinum spiral, and refused to move. When the candle was quite close it overcame the interfercnce, and the discs revolved in an irregular jerky manner. In three or four days the electrical disturbance was sufficiently diminished to enable me to proceed with my experiments, but I could detect the influence for weeks after.

One pole of a small induction-coil capable of giving half-inch sparks in air, was fastened to the platinum loops, the other pole being held by an insulating handle. The loose pole was then brought near the bulb. The nearest disc rushed round to it and followed it a little, then it stuck as if the glass were electrified. By gently moving the loose pole round I could get the arms to rotate in either direction, and they would keep on for fivo misutes or more when once started. These movements appear all to be explained by the known laws of static electricity, the rotations being of the "electrical fly" kind.

I obtained rotation in a radiometer without having the surfaces of the discs differently coloured. One having the pith discs lamp-blacked on both sides, and weighing I.25 grain, was exhausted with a charcoal tube attached. On a candle being brought near it, the arms moved until two of the discs were equidistant from the flams, and no amount of initial impulse in either direction would set it in rotation. A piece of ice caused it to move until one disc pointed to the ice, when it also stopped, but by shading the candle with a screen, so that the light shone on only one half of the tube, rapid rotation commenced, which, by altering the position of the screen to the other side, was instantly stopped, and changed into as rapid rotation in the opposite direction.

To enable me to exhibit the movement of a radiometer to a large audience I have made an instrument, the discs of which are of thin glass, silvered and polished on one side, and coated with lampblack on the otlzer. Owing to its great weight the movement is somewhat slow, but in the sun, or, with a strong light shining on the instrument, it is very striking, as it shows discs of light chasing each other round the room.

To communicate motion from the interior of the bulb to the outside, a radiometer was made which would carry round a magnet. Outside the bulb of this instrument I suspended, in a vertical position, a smaller magnet having the south pole at the top and the north pole at the bottom; this oscillates to and fro with every revolution of the radiometer, and making contact at the bottom, carries an electric current from a battery to a Morse instrument through which a ribbon of paper is drawn by clockwork 
so that at each revolution of the radiometer a record is printed on the strip of paper by dots; close together if the radiometer revolves quickly, farther apart if it goes slower.

The power of the earth on the magnet is too great to ailow the radiometer to start without some initial impetus; there should therefore be an astatic combination inside the bulb, but for a single experiment it may be set going by placing a few coils of insulated copper wire outside the bulb and depressing the battery key for an instant. An electric current is thus passed through the coils of wire, and the interior magnet is immediately deflected from its north-south position; the impetus thus gained enables the light to keep up the rotation.

For the purpose of measuring the amount of force exerted by radiation I constructed a torsion balance capable of indicating the millionth of a grain. A light beam having two square inches of pith at one end is alanced on a fire fibre of glass ${ }^{1}$ stretched horizontally in a tube, one end of the fibre being connected with a torsion handle passing through the tube, and indicating angular movements on a graduated circle. The beam is cemented to the torsion fibre, and the whole is enclosed in glass and connected with the mercury pump by a spiral fube and exhausted as perfectly as possible. A flat oblong piece of soft iron weighing accurately o'or grain is put into the cross tube under the pith surface. This weight can be picked up by a horse-shoe magnet outside the tube and dropped on any part of the pith. A mark is made at the exact centre of the pith surface, and by moving the magnet about it is easy to place the iron weight accurately on this mark. A ray of light from a lamp reflected from a mirror in the centre of the beam to a millimetre scale four feet off shows the slightest movement. When the reflected ray points to zero, a turn of the torsion handle in one direction or the other will raise or depress the pich end of the beam, and thus cause the index ray to travel along the scale to the right or to the left. It a smail weight is placed on one end so as to depress it, and the torsion handle is then turned, the tendency of the glass fibre to untwist itself will ultimately balance the downward pressure of the weight, and will again bring the index ray to zero. It was found that when the weight of the I-Iooth of a grain was placed on the pith surface the torsion handie had to be turned twenty-seven revolutions and $353^{\circ}$, or $10073^{\circ}$ before the beam became horizontal. The downward pressure of the $\mathrm{x}$-rooth of a grain was therefore equivalent to the force of torsion of the glass thread when twisted through $10073^{\circ}$.

I then found out the degree of delicacy of the balance. $x^{\circ}$ of torsion gave a very decided movenient of the index ray, a torsion of $10073^{\circ}$ balancing the 1 -rooth of a grain, while $100074^{\circ}$ overbalanced it. The balance will therefore turn to the $99-100,000,000$ th of a grain.

Weighed in this balance, the mechanical torce of a cardle 12 inches off was found to be 0.000444 grain; of a candle 6 inches off $0^{\circ} 001772$ grain. At half the distance the weight of radiation should be four times, or 0.001776 grain; the difference between theory and experiment being only four millionths of a grain is a sufficient proof that the indications of this instrument follow rigidly the law of inverse squares. An examination of the differences between the separate observations and the mean shows that my estimate of the sensitiveness of this balance is not excessive, and that in practice it will safely indicate the millionth of a grain.

I performed an experiment at the meeting of the Royal Society on March 30 last to demonstrate the movement of the glass case of the radiometer. I made use of a large radiometer in a 4-inch bulb with ten arms, eight of

I The torsion of fibre must be selected with great care. Ten threads were drawn out before the blowpipe and suspended from a horizontal beam. Weights were then gradually hung on to the lower ends. Only two were found strang enough The one selected stood $45^{\circ}$ grains without breaking, its diamster being less than oor incli. which were brass, and the other two a long watch-spring magnet. The discs were of pith blackened on one side.

The instrument was floated in a vessel of water, four candles being placed round it to set the arms in rotation. A mark was put on the glass envelope to enable a slight movement to be seen.

A powerful magnet was now brought near the moving: arms, which immediately stopped, and at the same time the glass envelope commenced to revolve in the opposite direction to that in which the arms had been revolving. The movement kept up as lono as the candles were burning, and the speed was one revolution in two minutes. On the magnet being removed the arms obeyed the force of radiation from the candles and revolved rapidly, whilst the glass envelope quickly came to rest. The candles were then blown out, and as soon as the whole instrument had come to rest, a bar-magnet was moved alternately from one side to the other of the radiometer, so as to cause the vanes to rotate as if they had been under the influence of a candle. The glass envelope moved about one revolution in three minutes in the same direction as the arms, and on reversing the direction of movement of arms, the glass envelope changed direction also. This I consider is proof that the internal friction, either of the steel point on the glass socket or the vanes against the residual air, or of both these causes combined, is considerable. Moving the vanes round by the exterior magnet carries the whole envelope round in opposition to the friction of the water against the glass.

In another communication I propose to give the results of my experiments on the influence of the residual gas on the movement of the radiometer, and also refer to other results which I have recently obtained.

William CROOKeS

\section{ON A NEW ASTRONOMICAL CLOCK"}

7 HE object of this communication was to explain to members of the Association and give them ari opportunity of sceing in my house in the University a clock which had been described in a communication to the Royal Society, in 1859, entitled "On a New Astronomical Clock and a. Pendulum Governor for Uniform Motion." The following description is taken from the Proceedings of the Royal Society for I869, except a few alterations and additions, and except the drawings, which have not been hitherto published :--

It seems strange that the dead-beat escapement should still hold its place in the astronomical clock, when its geometrical transformation, the cylinder escapement of the same inventor, Graham, only survives in Geneva vatches of the cheaper class. For better portable timekeepers it has been altered, through the vicious rack-andpinion movement, into the superlatively good detached lever. If it is possible to make astronomical clocks go better than at present by merely giving them a better escapement, it is quite certain that one on the same principle as the detached lever, or as Earnshaw's shipchronometer escapement, would improve their timekeeping.

But the irregularities hitherto tolerated in astronomical clocks may be due more to the faultiness of the steel and mercury compensation pendulum, with its loosely attached glass jar, and of the mode in which it is hung, and to instability of the supporting clock-case or framework, than to imperfection of the escapement and the greatness of the arc of vibration which it requires; therefore it would be wrong to expect confidently much improvement in the time-keeping merely from improvement of the escapement. I have therefore endeavoured to improve both the compensation for change $x$ " On a New Form of Astronomical Clock with Free Pendulum and Independently Governed Uniform Motion for Escapement Wheel." By Prof. Sir William Thomson, F.R.S. (Communicated to Section A of the British Association, Thursday, September 7, 1876.) 